\title{
On the representation of capsizing in iceberg models
}

\author{
Till J.W. Wagner ${ }^{\mathrm{a}, *}$, Alon A. Stern ${ }^{\mathrm{b}}$, Rebecca W. Dell ${ }^{\mathrm{a}}$, Ian Eisenman ${ }^{\mathrm{a}}$ \\ a Scripps Institution of Oceanography, University of California San Diego, United States \\ ${ }^{\mathrm{b}}$ Geophysical Fluid Dynamics Laboratory, Princeton University, United States
}

\section{A R T I C L E I N F O}

\section{Article history:}

Received 6 February 2017

Revised 2 June 2017

Accepted 20 July 2017

Available online 21 July 2017

\section{Keywords:}

Icebergs

Capsizing

Meltwater

Stability

Modelling

\begin{abstract}
A B S T R A C T
Although iceberg models have been used for decades, they have received far more widespread attention in recent years, due in part to efforts to explicitly represent icebergs in climate models. This calls for increased scrutiny of all aspects of typical iceberg models. An important component of iceberg models is the representation of iceberg capsizing, or rolling. Rolling occurs spontaneously when the ratio of iceberg width to height falls below a critical threshold. Here we examine previously proposed representations of this threshold, and we find that there have been crucial flaws in the representation of rolling in many modeling studies to date. We correct these errors and identify an accurate model representation of iceberg rolling. Next, we assess how iceberg rolling influences simulation results in a hierarchy of models. Rolling is found to substantially prolong the lifespan of individual icebergs and allow them to drift farther offshore. However, rolling occurs only after large icebergs have lost most of their initial volume, and it thus has a relatively small impact on the large-scale freshwater distribution in comprehensive model simulations. The results suggest that accurate representations of iceberg rolling may be of particular importance for operational forecast models of iceberg drift, as well as for regional changes in high-resolution climate model simulations.
\end{abstract}

(C) 2017 Elsevier Ltd. All rights reserved.

\section{Introduction}

The drift and decay of icebergs has received increasing interest in recent years associated with several factors. (i) Icebergs pose a threat to high-latitude shipping, as well as to offshore hydrocarbon exploration efforts. The rapid retreat of Arctic sea ice and concurrent increases in oil and gas demands have increased shipping through the Arctic (Pizzolato etal., 2014) and discussions of drilling operations in the Arctic Ocean (Unger, 2014; Henderson and Loe, 2016). (ii) Global warming, and particularly high temperatures observed around Greenland and the Antarctic Peninsula, are being linked to increases in the flux of icebergs calving from glaciers and ice shelves. Calving rates are thus projected to accelerate during the coming decades (e.g., Rignot and Kanagaratnam, 2006; Copland et al., 2007; Rignot et al., 2011; Joughin et al., 2014). (iii) An increased incidence of icebergs is projected to impact regional ecosystems and oceanographic conditions (e.g., Vernet et al., 2012; Smith etal., 2013; Stern etal., 2015; Duprat etal., 2016). (iv) Icebergs carry and release freshwater far from the calving source (Silva etal., 2006; Rackow etal., 2017), and they can affect the large-scale ocean circulation (e.g., Martin and Adcroft, 2010;

\footnotetext{
* Corresponding author.

E-mail address: tjwagner@ucsd.edu (T.J.W. Wagner).
}

Stern etal., 2016); (v) As an extreme example of this, the release of massive armadas of icebergs from the Laurentide Ice Sheets during the Heinrich Events of the last glacial period are believed to have affected Earth's climate globally (see e.g., Broecker, 1994; Stokes etal., 2015). In light of these factors, icebergs are being increasingly represented in climate models of varying complexity, ranging from Earth System Models of Intermediate Complexity (EMICs) (e.g., Jongma etal., 2009; 2013; Bügelmayer etal., 2015), to high-resolution ocean models (e.g., Marsh etal., 2015; Merino et al., 2016), to state-of-the-art comprehensive global climate models (GCMs) (e.g., Martin and Adcroft, 2010; Hunke and Comeau, 2011; Stern et al., 2016).

The fate of an iceberg is determined by a number of processes. Iceberg trajectories are strongly dependent on the shape and size of the iceberg, so as an iceberg decays, the forces acting on it change. Some of the decay is continuous and takes place in the form of gradual ablation. However, there are several iceberg processes that are inherently less continuous and complicate model representations of iceberg drift and decay, such as fracture and breakup, grounding events, and capsizing. This study focuses on the latter phenomenon.

Section 2 reviews previously proposed model representations of iceberg capsizing. These rolling criteria assume that an iceberg will roll once a critical width-to-height ratio has been crossed. However, previous studies disagree on the value of this ratio. 

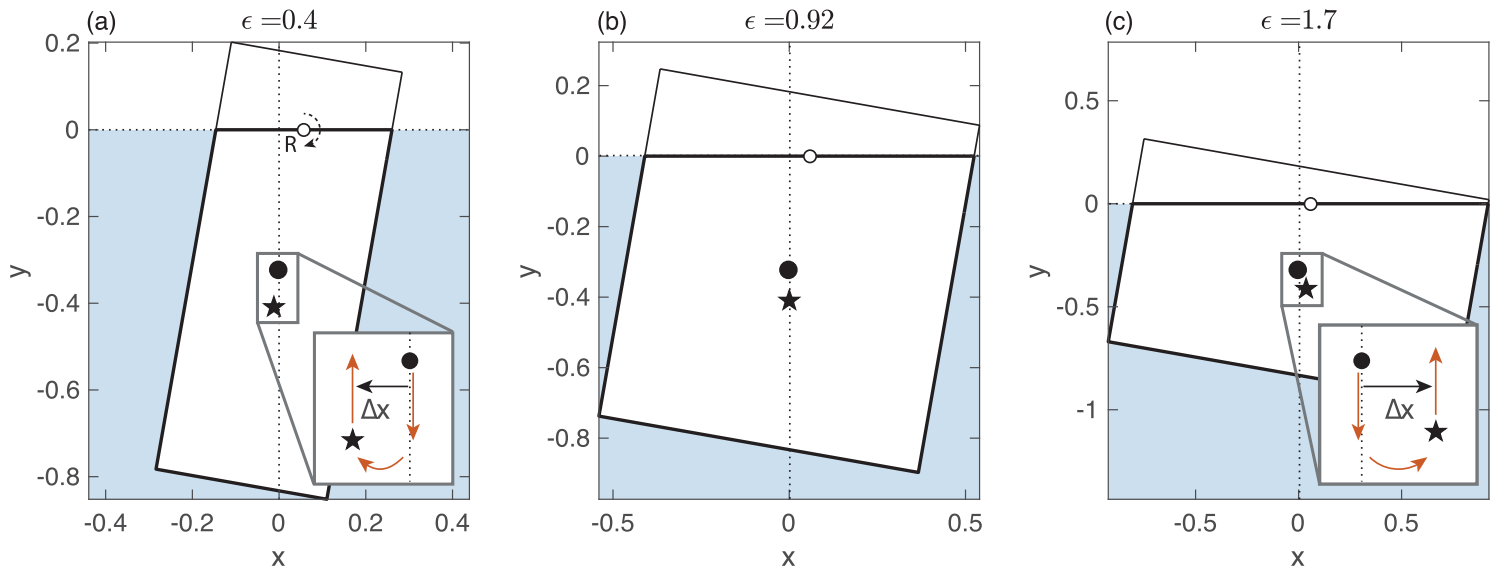

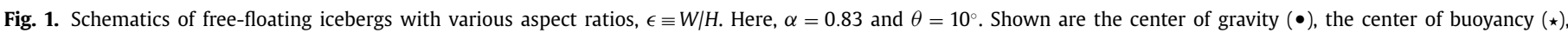

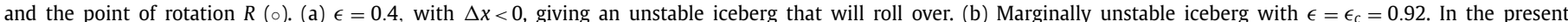

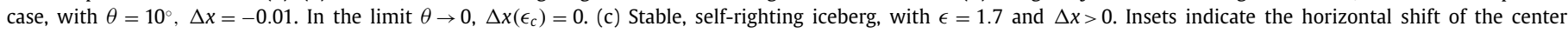

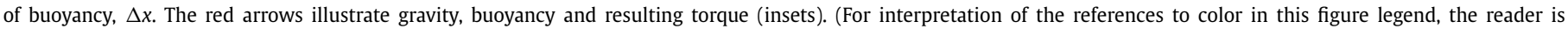
referred to the web version of this article.)

Section 3 investigates how rolling impacts the evolution of individual iceberg geometries and their overall lifespan, compared to simulations with icebergs undergoing no rolling. In Section 4, we consider the effect of rolling in a global climate model, focusing on iceberg meltwater distributions at the ocean surface. Conclusions are given in Section 5 .

\section{Rolling criteria}

In what follows, we idealize icebergs to be cuboids, allowing us to consider their stability from a 2D cross-sectional perspective. Icebergs roll along the long axis, $L$, swapping height, $H$, and width, $W$. We further assume that icebergs are always in isostatic equilibrium and of uniform ice density, $\rho_{i}$. We define the density ratio $\alpha \equiv \rho_{i} / \rho_{w}$, where $\rho_{w}$ is the density of water.

We will show that an iceberg is subject to rolling under infinitesimal perturbations when its width-to-height ratio, $\epsilon \equiv W / H$, is smaller than a given critical value, $\epsilon_{c}$. For $\epsilon>\epsilon_{c}$, on the other hand, the iceberg will return to its original position following an infinitesimal perturbation.

An expression for $\epsilon_{c}$ was previously derived by MacAyeal et al. (2003), who evaluated the change in gravitational potential energy under small rotations for an ice-shelf fragment wedged between two segments of an ice shelf. This derivation was later applied to free floating icebergs by Burton etal. (2012), who performed laboratory experiments to test the criterion.

Here, we present an alternative derivation of $\epsilon_{c}$ by considering the torques acting on an iceberg after it is rotated: for a given clockwise rotation, $\theta$, around point $R$ (Fig. 1 ), the center of buoyancy of the submerged part of the iceberg will shift horizontally by a distance $\Delta x$ relative to the center of gravity. It can be shown trigonometrically that this horizontal shift is

$\Delta x=\frac{H}{2}\left[\left(\alpha-1+\frac{\epsilon^{2}}{12 \alpha}\right) \sin \theta+\frac{\epsilon^{2}}{12 \alpha} \sec \theta \tan \theta\right]$

(see derivation in the Supplemental Information). Note that Eq. (1) holds only in the range of $\theta$ for which the top surface of the iceberg remains entirely above sea level, $0 \leq \theta<$ $\tan ^{-1}(2(1-\alpha) / \epsilon)$.

If $\Delta x>0$, the counter-clockwise torque that results from the offset of the downward acting gravitational force and the upward acting buoyancy force opposes the direction of rotation, and it acts to restore the original equilibrium. This is the case for shallow wide icebergs (i.e., large $\epsilon$ ), where we can approximately neglect horizontal motion due to rotation and consider only that the left side is raised and the right side is lowered, leading to additional submerged ice to the right of the center of gravity (Fig. 1(c)). When $\Delta x<0$, on the other hand, this torque acts in the direction of rotation, and the iceberg becomes unstable (Fig. 1(a)). This is the case for tall narrow icebergs (i.e., small $\epsilon$ ), where we can approximately neglect vertical motion due to rotation and consider only that the top half is shifted right and bottom half is shifted left, leading to additional submerged ice to the left of the center of gravity.

We are interested in the response of the iceberg to infinitesimal perturbations, that is, for $\theta \rightarrow 0$. We compute the Taylor series of Eq. (1) for $\theta$ around zero, which gives

$\Delta x=\frac{H}{2}\left(\alpha-1+\frac{\epsilon^{2}}{6 \alpha}\right) \theta+\mathcal{O}\left(\theta^{2}\right)$.

The critical width-to-height ratio at which the iceberg becomes unstable under small perturbations can then be defined as $\epsilon_{c} \equiv \epsilon$ when $\Delta x=0$ and $\theta \rightarrow 0$. From Eq. (2), we find

$\varepsilon_{c}=\sqrt{6 \alpha(1-\alpha)}$.

Note that under finite perturbations $\theta$, icebergs with aspect ratios larger than $\epsilon_{c}$ may become unstable and capsize (MacAyeal et al., 2003; Burton et al., 2012).

An iceberg rolling criterion that is widely used in current iceberg models was introduced by Weeks and Mellor (1978) (henceforth, WM78). WM78 derived a rolling criterion using insights from the ship-building literature (see Supplementary Information), leading to an expression similar to (3). However, WM78 further accounted for an increase in ice density with depth by introducing a correction height, $\Delta$. In this case, it can be shown that the rolling criterion should become

$\epsilon_{c}=\sqrt{6 \alpha(1-\alpha)-12 \alpha \frac{\Delta}{H}}$

(A derivation of criterion (4) is provided in the Supplementary Information.) In agreement with physical intuition, the increase in density with depth leads to a lower value of $\epsilon_{c}$. However, we find that the derivation in WM78 erroneously replaced $\Delta$ with $-\Delta$ in the stability criterion [see their equation (9)], an error that does not appear to have been noted in the literature previously and has been carried in many subsequent studies, as discussed below.

WM78 estimated the effective mean density ratio to be $\alpha=$ 0.81 . By substituting $\alpha=0.81$ into (4) and replacing $\Delta$ with $-\Delta$, we find that the sign error in $\Delta$ leads to $\epsilon_{c}>1$ for $H<730 \mathrm{~m}$. 


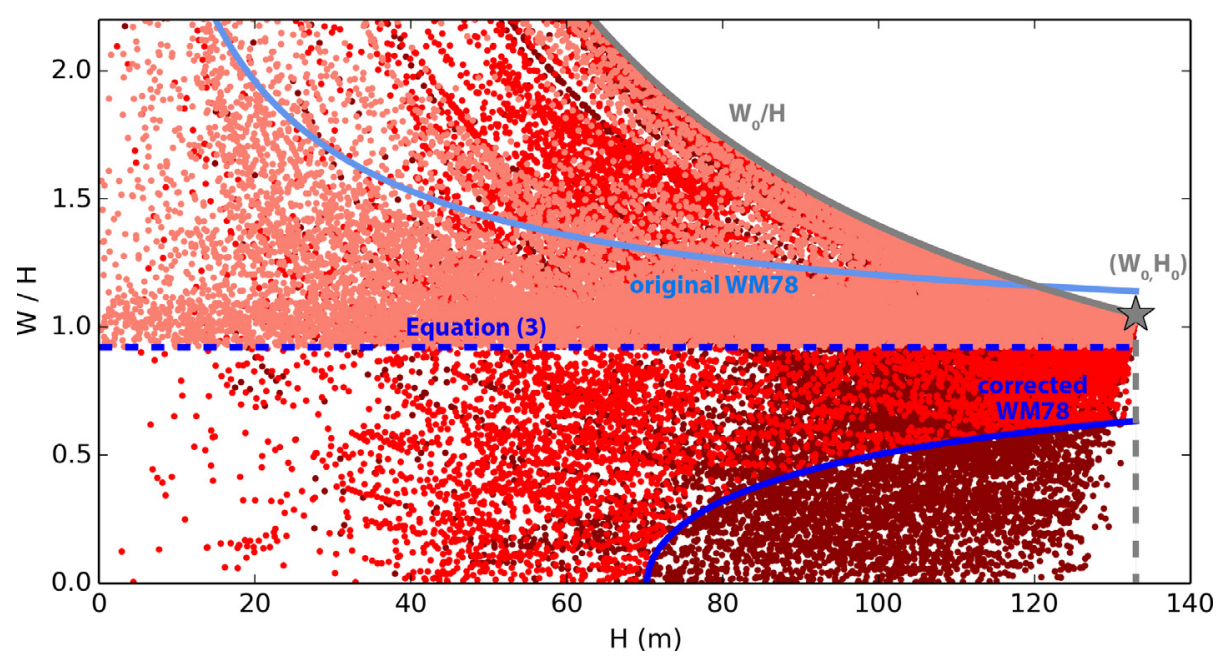

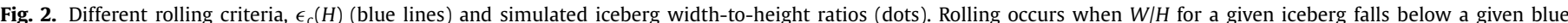

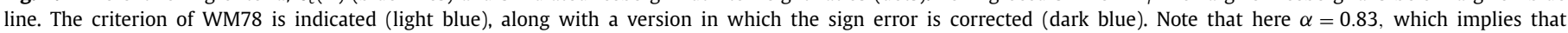

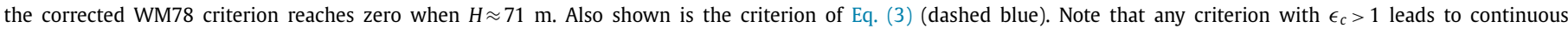



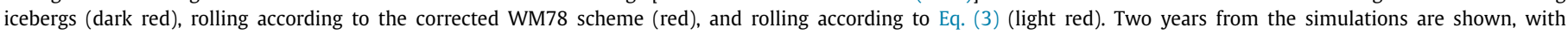

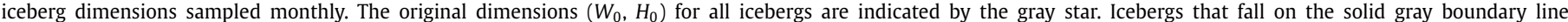

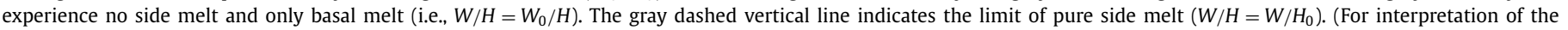
references to color in this figure legend, the reader is referred to the web version of this article.)

Among other issues, this has the unphysical consequence that all icebergs with $H<730 \mathrm{~m}$ will continuously roll once $\epsilon$ falls below $\epsilon_{c}$. In other words, once the $200 \mathrm{~m}$ thick icebergs considered in WM78 capsize for the first time, they will continue to roll at each model time step.

WM78 were primarily concerned with an idealized iceberg of thickness $H=200 \mathrm{~m}$, and they approximated the center of gravity correction to be constant, with $\Delta=6 \mathrm{~m}$. It should be emphasized that even the corrected WM78 formulation is not appropriate for use in the continuous evolution of a decaying iceberg. First, when the iceberg thickness changes, $\Delta$ should evolve rather than being held constant. This issue is especially egregious for small icebergs, where $\Delta=6 \mathrm{~m}$ places the center of gravity of the iceberg so low that the iceberg is unconditionally stable. A consequence of this is that $\epsilon_{c}$ is no longer defined when $H<12 \Delta / 6(1-\alpha) \approx 63 \mathrm{~m}$ (for the values used in WM78), and icebergs no longer roll in model simulations, which allows narrow, pin-like icebergs to occur (Fig. 2). Second, the density profile of the iceberg assumed in the WM78 derivation (i.e., that icebergs are densest near the bottom) would be rotated by $90^{\circ}$ upon the first instance of rolling, rendering Eq. (4) no longer appropriate.

However, the criterion of WM78 has been adopted by many studies of continuous iceberg evolution, which have applied the criterion under a broad range of iceberg dimensions. For example, the rolling criterion (including the sign error and constant value of $\Delta$ ) is adopted in the seminal study of Bigg etal. (1997), who consider icebergs of 10 different size classes ranging from $100 \mathrm{~m} \times$ $66 \mathrm{~m} \times 80 \mathrm{~m}$ to $1500 \mathrm{~m} \times 1000 \mathrm{~m} \times 360 \mathrm{~m}$. In addition to adopting the sign error from WM78, the model of Bigg etal. (1997) also erroneously takes the critical threshold to apply to the ratio $L / H$ rather than $W / H$. In other words, the horizontal length dimension that is used for the rolling criterion is not the same as the dimension that is rotated from horizontal to vertical when the iceberg rolls. All of these errors - the sign error in $\Delta$, the constant value of $\Delta$ associated with $H=200 \mathrm{~m}$ being applied to a wide range of iceberg thicknesses, and the threshold applying to $L / H$ - are adopted in the more recent iceberg modeling studies of Gladstone etal. (2001), Jongma etal. (2009), and Martin and Adcroft (2010). Martin and Adcroft (2010) furthermore erroneously replace $H$ with the draft $\alpha H$ in their representation of the rolling criterion (4). The model of Bigg et al. (1997) has been widely adopted, and many recent iceberg modeling studies include these errors in the rolling scheme (e.g., Death et al., 2006; Levine and Bigg, 2008; Wiersma and Jongma, 2010; Jongma etal., 2013; Death et al., 2014; Roberts etal., 2014; vanden Berk and Drijfhout, 2014; Bügelmayer et al., 2015; Marsh etal., 2015; Merino etal., 2016; Stern et al., 2016).

In order to take into account the varying density profile of an iceberg, a more complete theory of the density evolution of the iceberg would have to be developed. However, the constant density criterion in Eq. (3) may provide a sufficiently accurate approximation for many purposes.

Based on observed ice-shelf densities from Larsen $A$ and B, MacAyeal etal. (2003) estimated $\epsilon_{c} \simeq 0.8$, which is close to the value of WM78 and subsequent studies, while Burton et al. (2012) use $\epsilon_{c}=0.75$. In the following, we take $\rho_{i}=850 \mathrm{~kg} / \mathrm{m}^{3}$ (Silva etal., 2006) and $\rho_{w}=1025 \mathrm{~kg} / \mathrm{m}^{3}$, such that $\alpha=0.83$ (Martin and Adcroft, 2010; Stern et al., 2016), which gives $\epsilon_{c} \simeq 0.92$. Note that this value of $\rho_{i}$ is lower than for pure ice due to factors including the snow and firn in the iceberg not being fully compacted. The stability criterion from Eq. (3), as well as the original and corrected WM78 schemes, are illustrated in Fig. 2.

\section{Impact of rolling on individual icebergs}

In order to study the impact that rolling has on individual icebergs, we will compare two scenarios: (i) icebergs undergoing no rolling and (ii) icebergs that roll according to the scheme in Eq. (3). We eschew the WM78 scheme in this section in light of the issues raised above. We briefly revisit the WM78 scheme for the GCM simulations in Section 4 in order to estimate the potential bias that the errors in this scheme may have introduced in previous studies.

\subsection{Iceberg decay model}

We first summarize the widely used decay representation by Martin and Adcroft (2010), which is based on the earlier work by Bigg etal. (1997). In this formulation, only three melt processes are considered: (i) wind-driven wave erosion, $M_{e}$; (ii) turbulent basal melt, $M_{b}$; and (iii) side wall erosion from buoyant convection, $M_{v}$. Other processes, such as top and bottom surface melt, 
are typically small compared to these (Savage, 2001). The iceberg dimensions evolve according to $d L / d t=d W / d t=M_{e}+M_{v}$ and $d H / d t=M_{b}$, with iceberg volume given by $V=L W H$. The individual decay terms are written as follows (Martin and Adcroft, 2010; Wagner and Eisenman, 2017):

$M_{e}=\frac{1}{2}\left(1+\cos \left[\pi A_{i}^{3}\right]\right)\left(p_{1}+p_{2} T_{w}\right) S\left(\vec{v}_{a}, \vec{v}_{w}\right)$,

$M_{v}=b_{1} T_{w}+b_{2} T_{w}^{2}$,

$M_{b}=c\left|\vec{v}_{w}-\vec{v}_{i}\right|^{0.8}\left(T_{w}-T_{i}\right) L^{-0.2}$,

where $A_{i}$ is the fractional sea ice cover, $p_{1}=0.67, p_{2}=0.33^{\circ} \mathrm{C}^{-1}$, and $T_{w}$ is the SST in ${ }^{\circ} \mathrm{C}$. Sidewall erosion is set to $M_{v}=0$ if $T_{w}<0{ }^{\circ} \mathrm{C}$. Here, $S=a_{1}\left|\vec{v}_{a}-\vec{v}_{w}\right|^{1 / 2}+a_{2}\left|\vec{v}_{a}-\vec{v}_{w}\right|$ is related to the sea state (Martin and Adcroft, 2010), with $a_{1}=8.7 \times 10^{-6} \mathrm{~m}^{1 / 2} \mathrm{~s}^{-1 / 2}$ and $a_{2}=5.8 \times 10^{-7}$. Furthermore, $b_{1}=8.8 \times 10^{-8} \mathrm{~m} \mathrm{~s}^{-1^{\circ}} \mathrm{C}^{-1}, b_{2}=$

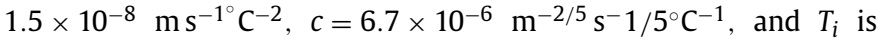
the temperature of the ice which is taken to be fixed at $-4^{\circ} \mathrm{C}$.

\subsection{Rolling under constant forcing}

In order to estimate how rolling impacts the evolution of the iceberg, it is useful to first consider average forcing conditions. From the GCM simulations of Section 4 we find that average speeds experienced by present-day icebergs are approximately $\left|\vec{v}_{a}\right|=3$ $\mathrm{m} / \mathrm{s},\left|\vec{v}_{w}\right|=0.04 \mathrm{~m} / \mathrm{s}$, and $\left|\vec{v}_{i}\right|=0.06 \mathrm{~m} / \mathrm{s}$, and average SSTs are approximately $T_{w}=-1.2^{\circ} \mathrm{C}$. This low temperature value is largely due to the simulated present-day icebergs spending a large fraction of their life surrounded by sea ice (average $A_{i}=0.75$ ). For these average forcing values, we obtain $M_{e} \sim 0.3 \mathrm{~m} / \mathrm{d}, M_{b} \sim 0.06$ $\mathrm{m} / \mathrm{d}$, and $M_{v} \sim 0.004 \mathrm{~m} / \mathrm{d}$. Note that the dominance of the winddriven wave erosion term is in agreement with previous findings (e.g., Gladstone etal., 2001). The evolution of the individual dimensions of a non-rolling and a rolling iceberg are illustrated in Fig. 3(a) and (b), using the melt rates above and ignoring the effects of iceberg drift. The figure shows that rolling slows down an iceberg's melt. The reason for this is that for all realistic values of $\alpha$, the critical ratio satisfies $\epsilon_{c}<1$, i.e., $W<H$ at the time of rolling. This implies that the surface area of the sidewalls, $A=2 H(W+L)$, decreases when the iceberg rolls (because $H$ and $W$ are swapped). As a consequence, the rate of volume loss decreases once rolling begins (Fig. $3(\mathrm{c})$ ), since $d V / d t \approx-A M_{e} / 2$ (neglecting the typically smaller terms $M_{b}$ and $M_{v}$ ).

3.2.1. Onset of rolling. As a first step, we set $M_{v}=M_{b}=0$, since both terms are typically considerably smaller than $M_{e}$. In this approximation, $H$ remains constant. For given initial iceberg dimensions, $H_{0}, W_{0}, L_{0}$, the critical width at which icebergs roll for the first time is then $W_{r}=\epsilon_{c} H_{0}$. Taking $L_{0} / W_{0}=3 / 2$, as is often done in current iceberg models, we find $L_{r}=\left(1 / 2+\epsilon_{c} / \epsilon_{0}\right) W_{0}$, where $\epsilon_{0} \equiv W_{0} / H_{0}$. The volume fraction at first rolling is then

$V_{r} / V_{0}=\frac{1}{3}\left(1+2 \epsilon_{c} / \epsilon_{0}\right)\left(\epsilon_{c} / \epsilon_{0}\right)$.

In order to study the onset of rolling for different initial iceberg sizes, we consider 10 commonly used iceberg size classes, ranging in dimensions from $60 \times 40 \times 40 \mathrm{~m}$ to $2200 \times 1467 \times 250 \mathrm{~m}$ (Table 1). For size classes $1-3, \epsilon_{0}=1$ and Eq. (6) gives $V_{r} / V_{0}=0.87$, i.e., the iceberg will roll for the first time once it is $13 \%$ decayed. For size classes 4-10, $\epsilon_{0}$ increases, which leads to a decrease in $V_{r} / V_{0}$. Fig. 3(d) summarizes how $V_{r} / V_{0}$ varies with size class, showing the analytical upper limit (6), as well as values that take into account nonzero values of $M_{v}$ and $M_{b}$. For size class 10 , the iceberg begins to roll when it is $98 \%$ decayed (considering all three melt terms). This highlights that iceberg rolling is most significant for small icebergs.
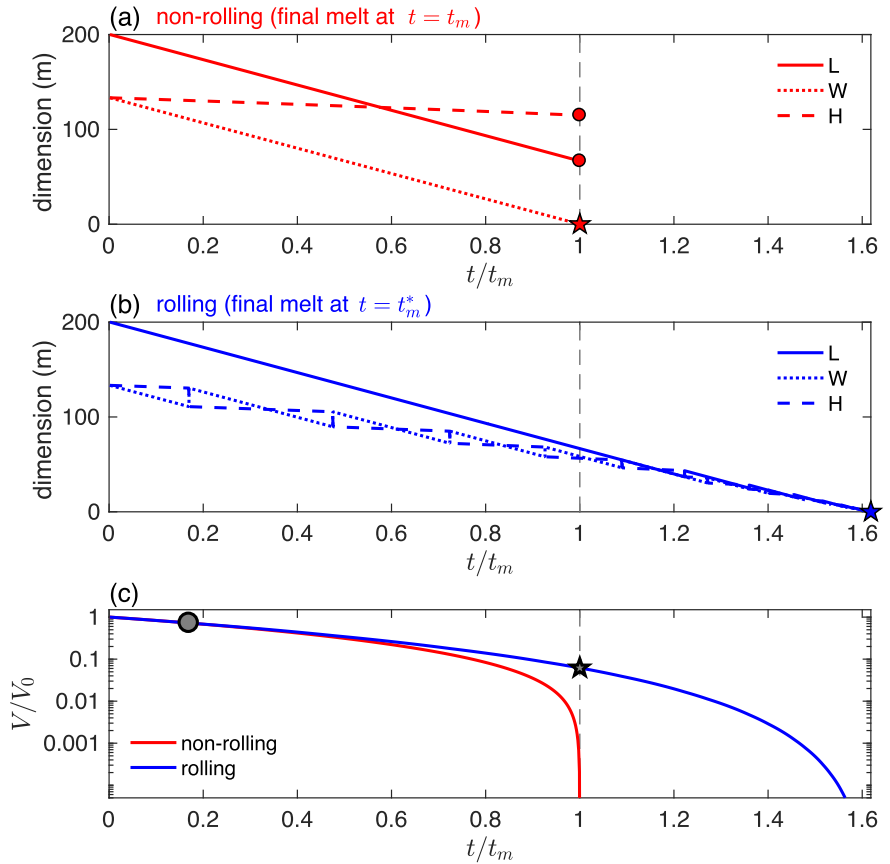

(d)

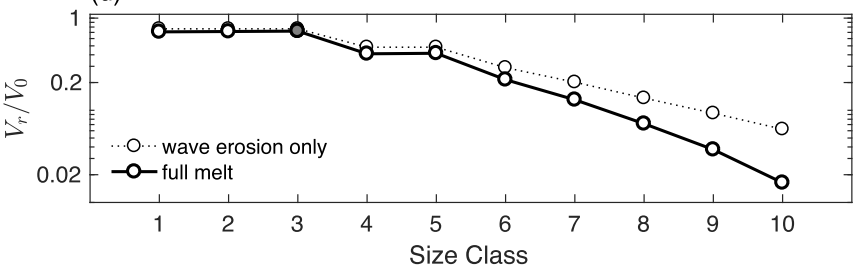

Fig. 3. Evolution of iceberg dimensions and volume in simulations with constant forcing. (a) Decay of a non-rolling iceberg of size class 3 using constant forcing values. Shown are dimensions $L$ (solid), $W$ (dotted), and $H$ (dashed) versus time (scaled by time of final melt, $t_{m}$ ). The iceberg has fully melted when $W=0$ (star). Unphysically, $L$ and $H$ have not reached zero (circles). (b) As in panel a, but including iceberg rolling. Note that here all dimensions reach zero at the same time, $t_{m}^{*}$ (star). (c) Volume scaled by initial volume corresponding to panels a and b. Symbols are included to indicate the volume at the time of initial roll (circle), as well as the remaining volume of the rolling iceberg when the non-rolling iceberg has melted (star). (d) Volume (scaled by initial volume) at the time of initial roll for the 10 size classes of Table 1 . The dotted line corresponds to the analytical upper limit of Eq. (6), which takes $M_{v}=M_{b}=0$. The gray circle corresponds to the gray circle in panel $c$.

Table 1

Initial iceberg dimensions and $\epsilon_{0} \equiv W_{0} / H_{0}$ for the 10 size classes used here (adapted from Stern et al. (2016), which is based on Gladstone et al. (2001)).

\begin{tabular}{lllll}
\hline Size Class & $L_{0}(\mathrm{~m})$ & $W_{0}(\mathrm{~m})$ & $H_{0}(\mathrm{~m})$ & $\epsilon_{0}$ \\
\hline 1 & 60 & 40 & 40 & 1 \\
2 & 100 & 67 & 67 & 1 \\
3 & 200 & 133 & 133 & 1 \\
4 & 350 & 233 & 175 & 1.3 \\
5 & 500 & 333 & 250 & 1.3 \\
6 & 700 & 467 & 250 & 1.9 \\
7 & 900 & 600 & 250 & 2.5 \\
8 & 1200 & 800 & 250 & 3.2 \\
9 & 1600 & 1067 & 250 & 4.3 \\
10 & 2200 & 1467 & 250 & 5.9 \\
\hline
\end{tabular}

3.2.2. Impact of rolling on iceberg life span. Under the approximation that $M_{b}=M_{v}=0$, a non-rolling iceberg would completely melt at time $t_{m}=W_{0} / M_{e}$, regardless of $L_{0}$. The time of complete melt for a rolling iceberg, on the other hand, can be readily shown to be

$t_{m}^{*}=\left[5 / 4+1 /\left(2 \epsilon_{0}\right)\right]\left(W_{0} / M_{e}\right)$,

where we again have fixed $L_{0} / W_{0}=3 / 2$. The relative life span of rolling versus non-rolling icebergs is then $t_{m}^{*} / t_{m}=5 / 4+1 / 2 \epsilon_{0}>1$, 
(a)
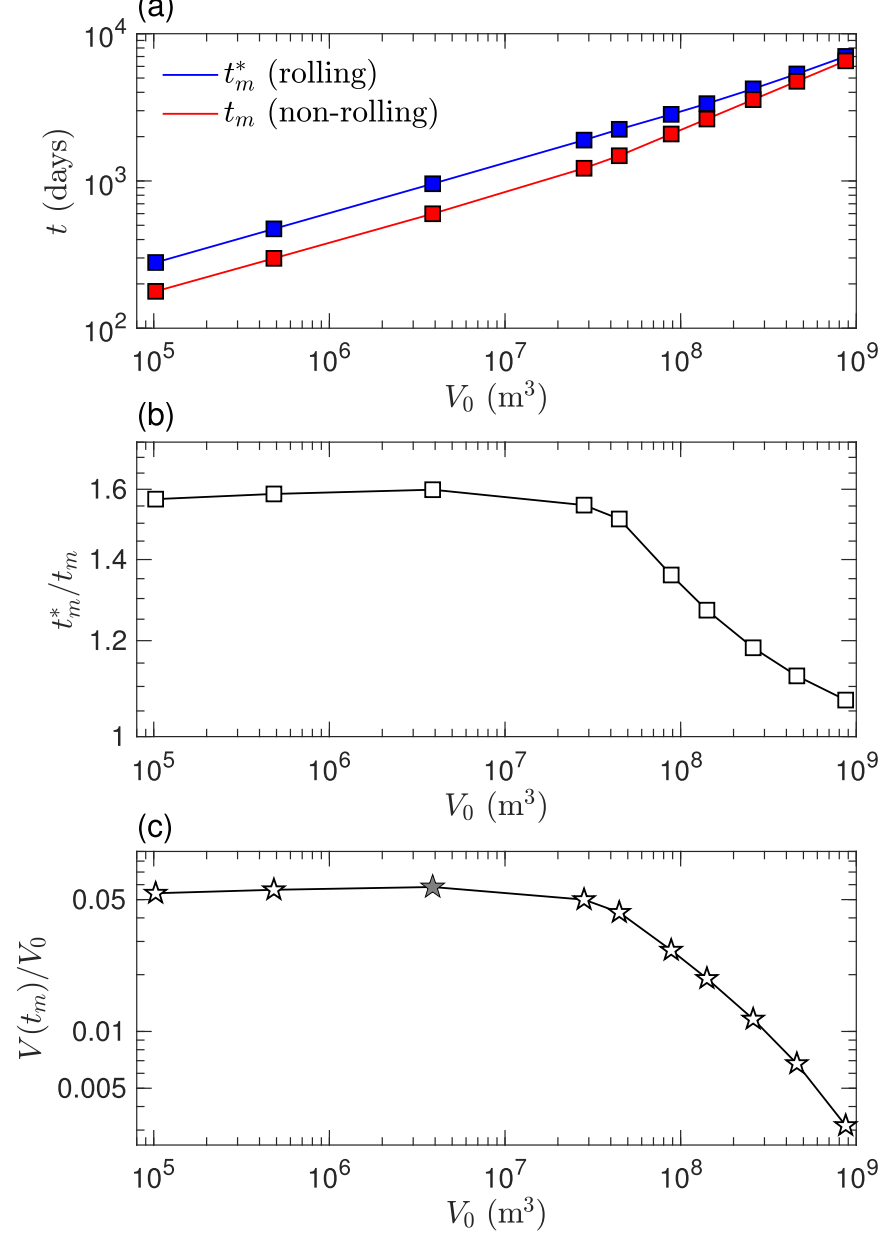

Fig. 4. Iceberg life spans in simulations with constant forcing. (a) Duration of iceberg life as a function of initial iceberg size, for size classes 1-10 (see text). (b) Ratio of iceberg lifespans with and without rolling, $t_{m}^{*} / t_{m}$, which shows that rolling icebergs of size classes 1-5 have lifespans about $60 \%$ longer than non-rolling icebergs. For large icebergs, $L$ is sufficiently large that it does not reach zero when $W$ and $H$ have fully melted. This results in a reduction of $t_{m}^{*} / t_{m}$ for large $V_{0}$. (c) Fraction of the volume of the rolling iceberg that remains at the time when the non-rolling iceberg disappears, $V\left(t_{m}\right) / V_{0}$. The gray star corresponds to the scenario in Fig. 3(a)-(c).

i.e., rolling icebergs always live longer (Fig.4(a)). Icebergs with a large initial width-to-height ratio, such that $\epsilon_{0} \rightarrow \infty$, live $25 \%$ longer. Icebergs in size classes $1-3$ (with $\epsilon_{0}=1$ ) live $75 \%$ longer due to rolling. Fig. 4(b) shows that, by accounting for $M_{b}$ and $M_{v}$, the actual increase in life span due to rolling for size classes 1-5 is closer to $60 \%$.

Note that Eq. (7) assumes constant forcing and neglects the impact of rolling on drift dynamics, which can also impact melt rates (see Section 4 ). Fig. 4(b) shows that $t_{m}^{*} / t_{m}$ decreases rapidly for large icebergs. For size classes $7-10, t_{m}^{*} / t_{m}$ falls below the limit $5 / 4$, which is due to $W$ and $H$ reaching zero before $L$ has melted completely. This highlights an unphysical feature in many current iceberg models: the models ultimately end up with long, infinitesimally thin icebergs. Finally, even though rolling icebergs can live substantially longer than non-rolling icebergs, the remaining volume at time $t_{m}$ (when the non-rolling iceberg has completely melted) is small, with $V\left(t_{m}\right) / V_{0}<6 \%$ (Fig. $4(\mathrm{c})$ ).

\section{Impact of rolling in iceberg-climate model simulations}

In what follows we compare the meltwater release in model simulations with rolling and non-rolling icebergs, using (1) an ide- alized iceberg drift and decay model and (2) a comprehensive coupled GCM.

\subsection{Idealized offline iceberg model}

We use a recently developed drift model which evolves iceberg velocity under the influence of air drag, water drag, the pressure gradient force, and the Coriolis force (Wagner et al., 2017). This formulation is somewhat idealized compared to previous iceberg models (e.g., Bigg etal., 1997; Gladstone et al., 2001; Marsh et al., 2015), allowing an analytical solution for iceberg velocity as a function of surface air and water velocities. The model operates in an offline mode, meaning that the iceberg trajectories are computed as non-interactive Lagrangian particles, using precomputed input surface velocity and SST fields. This allows for a rapid integration of large numbers of iceberg trajectories. The drift model is coupled to the decay model of Eq. (5).

The precomputed input fields are taken from NASA's Estimating the Circulation and Climate of the Ocean Phase II (ECCO2) global ocean state estimate (Menemenlis etal., 2008). We perform two sets of simulations, one with iceberg rolling using the scheme in Eq. (3) and one without iceberg rolling. In order to avoid canceling effects due to different iceberg release locations (see Section 4.2), we initialize icebergs in a small region just off the coast of Sermilik Fjord, East Greeland, into which Helheim Glacier, one of Greenland's largest outlet glaciers, drains (green star in Fig. 5(a)). The release location of each iceberg is set to be at the center of a grid box which is randomly chosen from a $5 \times 4$ region of grid boxes. Since this region only has substantial sea ice for a brief period of the year, we set the sea ice concentration to zero in the following simulations.

We release 5000 icebergs of each of the 10 iceberg size classes specified in Stern etal. (2016), at a rate of approximately 14/day, over the input year 1992. Icebergs are released at identical locations and times in the two simulations, and they are tracked until fully decayed.

Fig. 5 illustrates the results for size class 5, which are approximately representative of the other size classes (not shown). The longer life span and farther reach of rolling icebergs that are expected from the results of Section 3 are readily seen in these simulations. The blue and red dots in Fig. 5(a) show the final melting points of rolling and non-rolling icebergs, respectively. The nonrolling icebergs are found to typically melt closer to the release location compared to the rolling icebergs. Fig. 5(b)-(f) illustrates the evolution of a representative pair of rolling and non-rolling trajectories. The rolling iceberg survives $\sim 20 \%$ longer (Fig. 5(c)). The slow rate of decay over the first half of the icebergs' lives (Fig. 5(c)(e)) is due to cold winter conditions, and the melt rates speed up substantially during summer when the temperatures rise (Fig. 5(f)). Fig. 5(d) and (e) illustrate that the evolution of the simulated iceberg dimensions is comparable to that of the analytical version (Fig. 3(a) and (b)). The shorter relative life span of the rolling iceberg $\left(t_{m}^{*} / t_{m}=1.2\right)$, compared to the analytical value $\left(t_{m}^{*} / t_{m} \simeq 1.5\right.$ in Fig. 4(b)), is likely due to a number of factors, including higher values of $M_{e}$ once the iceberg reaches the warmer temperatures of the open ocean (Fig. 5(f)). Note that the rolling also has an immediate effect on the iceberg's drift direction. This is due to rolling changing the aspect ratio of the iceberg, and hence changing the momentum balance. This explains why the iceberg trajectories diverge upon the first rolling event $(t=161 \mathrm{~d})$, long before the final melt of the non-rolling iceberg $(t=228 \mathrm{~d}$, Fig. 5(b)). Furthermore, the change in aspect ratio from rolling causes the iceberg drift to slow (not shown), which reduces the spread of the rolling icebergs. This slowdown is a consequence of the horizontal iceberg surface area increasing when it rolls: iceberg drift velocities are dependent 
(a)

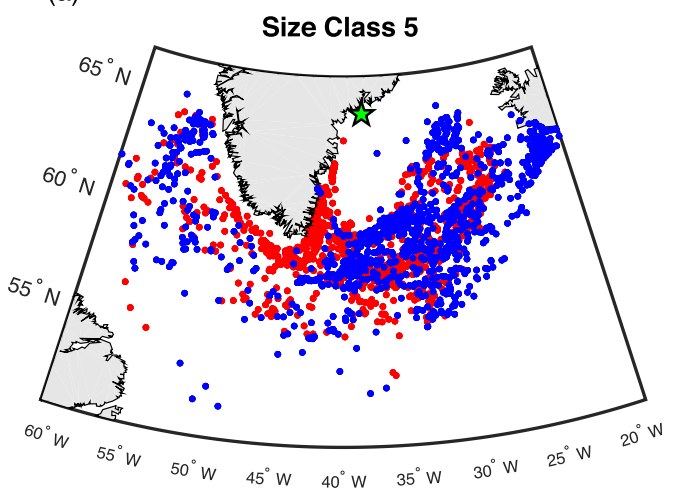

(b)



(c)

Trajectory 15

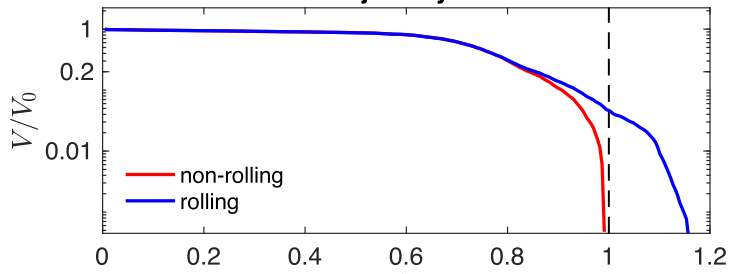

(d) non-rolling



(e) rolling



(f)

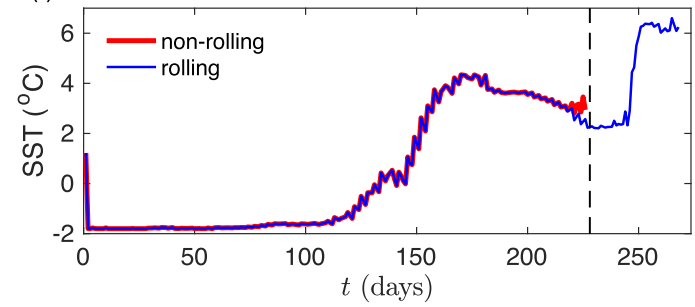

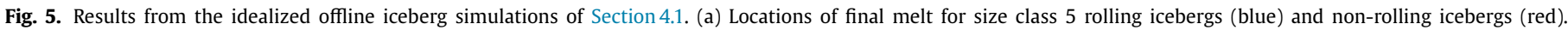



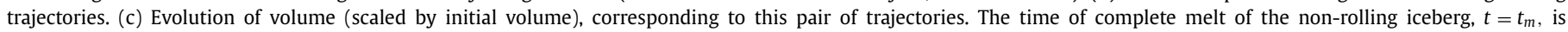


icebergs. (For interpretation of the references to color in this figure legend, the reader is referred to the web version of this article.)

on the horizontal surface area, with larger surface area reducing drift velocities (Wagner et al., 2017).

In order to assess the level of large-scale impacts of iceberg rolling, we consider simulations with a coupled GCM in the next section. This allows us to address the question whether the biases shown in Fig. 5(a) are substantial in comprehensive model runs, or whether they are small compared to the internal variability of the system.

\subsection{GCM Simulations}

We use the Geophysical Fluid Dynamics Laboratory (GFDL) coupled climate model CM2G (Delworth etal., 2006; Cooke etal., 2012), which includes the following components: AM2 atmosphere model, MOM6 ocean model, SIS2 sea-ice model, and LM3 land model, as well as the iceberg component detailed in Martin and Adcroft (2010). The ocean model uses a $1^{\circ} \times 1^{\circ}$ horizontal grid, with 63 isopycnal layers in the vertical, and the atmospheric model has a $2^{\circ}$ horizontal resolution. The model setup is as described in Stern etal. (2016), except for the iceberg rolling scheme. The icebergs in these simulations are fully coupled to the climate model, so that the melt water from the icebergs freshens and cools the ocean surface, which can lead to feedbacks in the climate system.

Icebergs are released into the global ocean according to the scheme of Stern etal. (2016), using the same 10 iceberg size classes, size class distributions, and release locations. CM2G computes iceberg calving fluxes by routing excess frozen precipitation over the ice sheets instantaneously to the coastline via hydraulic potential pathways. These locations encompass most major ice shelves and outlet glaciers in the Arctic and Antarctic. The simulations are run for 150 years each.

We perform three simulations: one with iceberg rolling using the scheme in Eq. (3), one with rolling using the WM78 scheme but with the error in the sign of $\Delta$ corrected, and one with no iceberg rolling. Icebergs in these simulations fill the phase space of available aspect ratios $(W / H)$, bounded by the critical rolling ratio $\epsilon_{c}$ and the limits $W_{0} / H$ and $W / H_{0}$ (see Fig. 2). The latter two limits indicate pure basal melt and pure sidewall melt, respectively. The large spread of simulated ratios in Fig. 2 indicates the wide range of ocean conditions and melt rates experienced by icebergs in different parts of the globe and at different times of the year.

Rolling is expected to have the greatest impact in the simulations that use Eq. (3), because rolling occurs much earlier than in those using the corrected WM78 scheme. Hence the following focuses on comparing simulations with non-rolling icebergs and icebergs that roll according to Eq. (3).

Fig. 6(a) and (b) show the freshwater flux due to iceberg melting around Antarctica and Greenland, averaged over the final 100 years of the simulations with the scheme from Eq. (3). These distributions are qualitatively similar to those in previous studies (e.g., 
(a)

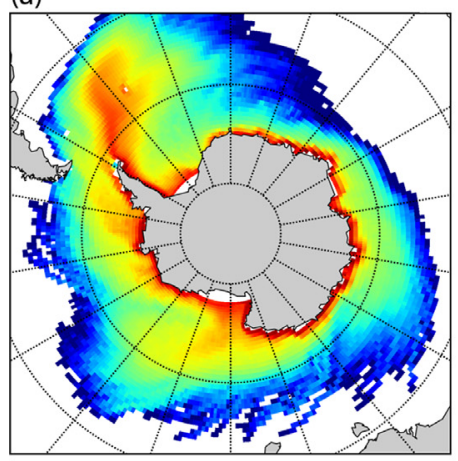

(c)



(b)



(d)

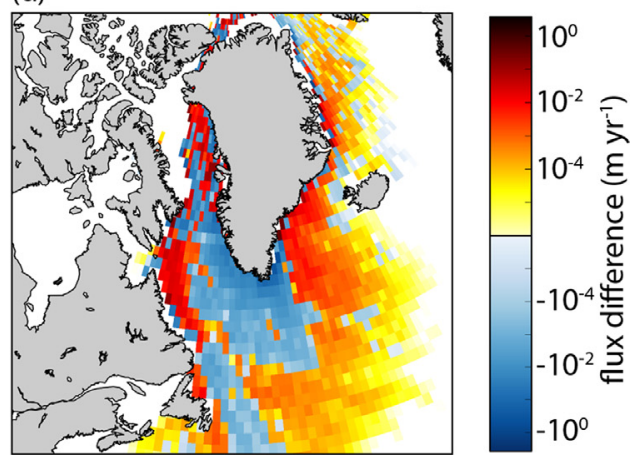

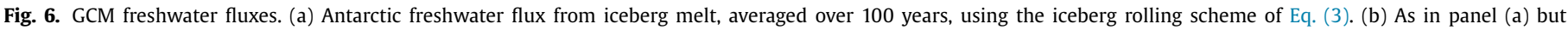

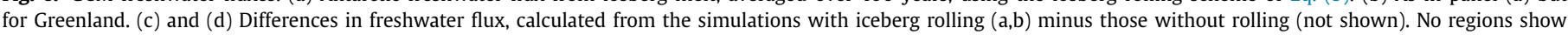
statistically significant differences. All fluxes are given in meters per year on a logarithmic scale.

Martin and Adcroft, 2010; Stern etal., 2016, who used the original WM78 scheme), which indicates that the differences in rolling schemes do not dramatically affect the large-scale freshwater flux distribution. This point is further supported when we compute the difference in freshwater flux between the rolling and non-rolling simulations in Fig. 6(c) and (d). The most notable differences in the Antarctic simulations are a slight increase of meltwater for rolling icebergs north of the Antarctic peninsula and a decrease around the peninsula's coast. This suggests that rolling allows icebergs to transport meltwater further offshore, in agreement with the findings of the previous section. A similar mechanism might be inferred from the differences around Greenland, where meltwater decrease near the southern tip of Greenland and a small increase off the Labrador coast suggests that rolling icebergs are transported further along the Greenland coastal currents. However, none of these differences are statistically significant at the 95\% confidence level over the time period of integration. The same result is found for simulations with the corrected WM78 scheme (not shown). The relatively small influence of rolling appears to be due to (i) the high level of internal variability of the overall freshwater forcing (which is strongly influenced by factors including the presence of sea ice which itself is highly variable), and (ii) the fact that rolling affects icebergs only after much of their initial volume has already melted, as discussed above (Fig. 3).

The small differences in the overall freshwater flux do not rule out that rolling icebergs may on average live longer or travel farther than their non-rolling counterparts, as may be expected from Sections 2 and 3. However, the wide range of ocean conditions which icebergs experience, together with the large internal variability in the coupled climate model, give rise to a large spread of iceberg lifetimes (Fig.7). Modeled iceberg lifetimes are, for example, sensitive to sea ice conditions, and can be greatly increased by icebergs becoming stuck along the Antarctic and Greenlandic

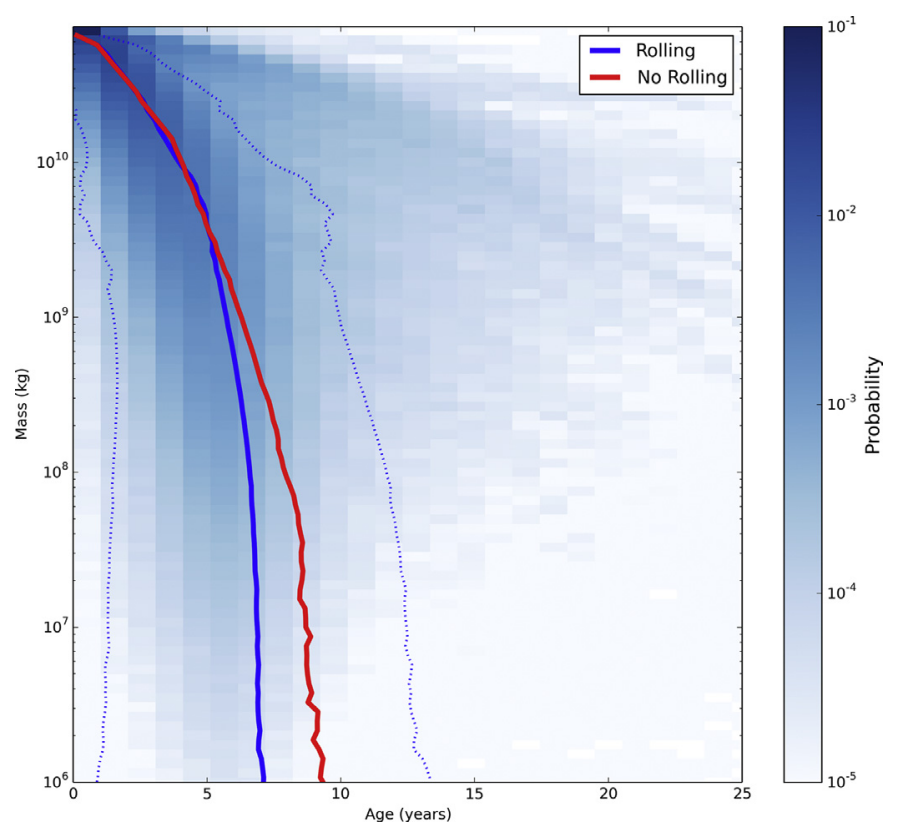

Fig. 7. Evolution of iceberg mass from GCM simulations for size class 10 (considering all icebergs in the global simulations). Shading shows relative probabilities of iceberg mass as a function of iceberg age for rolling icebergs, using the rolling scheme of Eq. (3). The corresponding probabilities for non-rolling icebergs (not shown) are qualitatively similar. Lines indicate the mean rolling (solid blue) and non-rolling (red) iceberg masses over time, as well as the spread of the rolling icebergs (dotted blue lines indicating one standard deviation about the mean). (For interpretation of the references to color in this figure legend, the reader is referred to the web version of this article.) 
coasts (factors that are not taken into account in the idealized model of Section 4.1). Furthermore, in the Northern Hemisphere icebergs decay more slowly if they drift into the central Arctic basin. Differences between Northern and Sothern Hemisphere lifetimes are illustrated in Fig. S3.

We find that in the GCM non-rolling icebergs live on average slightly longer than their rolling counterparts (contrary to the idealized model results of Sections 3.2 and 4.1), although Fig. 7 shows that this difference is small compared to the spread of simulated iceberg lifetimes. This slightly counter-intuitive result may be due to several factors: First, the high level of internal variability and long time scales of the coupled climate system result in different sea ice conditions for the two simulations, especially in the Northern Hemisphere (not shown). While these differences are not statistically significant when averaged over the 150 year simulation period, we do overall observe slightly warmer surface temperatures (and decreased sea ice) in the rolling simulation, which leads to more rapidly decaying icebergs. In addition to internal variability, iceberg lifetimes are influenced by their trajectories, as discussed above. After rolling, icebergs tend to spread more readily away from the coast (both in Antarctica and Greenland, see also Fig. 5(a)), causing them to be exposed to warmer waters. The combination of warmer conditions in the rolling simulation and more offshore trajectories for rolling icebergs appear to be sufficient to offset the decreases in iceberg decay caused by the geometric considerations of Section 3.

In summary, the findings of this section suggest that the largescale biases that are introduced in coupled climate simulations by the differences between these iceberg rolling schemes are relatively small.

\section{Conclusion}

In this study, we have addressed how to account for iceberg capsizing in models that explicitly represent icebergs. We have shown that a widely used rollover criterion, based on the work of Weeks and Mellor (1978), is not suitable to describe the rolling of icebergs for a typical range of iceberg sizes. The results presented here suggest that this criterion should be replaced by the more physical scheme in Eq. (3). For studies concerned with the detailed simulation of individual iceberg trajectories, however, a more sophisticated rolling scheme may be required.

We have found that rolling can substantially impact the drift and decay of individual icebergs, especially those that are relatively small (length $\lesssim 500 \mathrm{~m}$ ). For example, we find that for fixed surface velocities and SSTs, rolling icebergs typically live substantially longer and drift farther than non-rolling icebergs. This suggests that in regions where more small icebergs calve off glaciers or ice shelves, capsizing may have a large impact on meltwater fluxes. Hence the results presented here may be relevant to both operational iceberg forecast models and regional climate model simulations. Nonetheless, we have shown that iceberg rolling has a relatively small impact on the large-scale iceberg meltwater flux in the global climate system.

\section{Acknowledgments}

We are grateful to Jeff Severinghaus, Ralph Keeling, and Grant Bigg for helpful comments and discussions. This work was supported by National Science Foundation grant OCE-1357078.

\section{Supplementary material}

Supplementary material associated with this article can be found in the online version at 10.1016/j.ocemod.2017.07.003.

\section{References}

Bigg, G.R., Wadley, M.R., Stevens, D.P., Johnson, J.A., Oct. 1997. Modelling the dynamics and thermodynamics of icebergs. Cold Reg. Sci. Technol. 26 (October(2)), $113-135$.

Broecker, W.S., Dec. 1994. Massive iceberg discharges as triggers for global climate change. Nature 372 (6505), 421-424.

Bügelmayer, M., Roche, D.M., Renssen, H., 2015. How do icebergs affect the Greenland ice sheet under pre-industrial conditions? - a model study with a fully coupled ice-sheet-climate model. Cryosphere 9 (3), 821-835.

Burton, J.C., Amundson, J.M., Abbot, D.S., Boghosian, A., Cathles, L.M., Correa-Legisos, S., Darnell, K.N., Guttenberg, N., Holland, D.M., MacAyeal, D.R., 2012. Laboratory Investigations of Iceberg Capsize Dynamics, Energy Dissipation and Tsunamigenesis, 117. Norwegian Meteorological Institute.

Cooke, W., Dunne, K. A., Harrison, M. J., Malyshev, S. L., Milly, P. C. D., Sentman, L. T., Samuels, B. L., Spelman, M. J., Winton, M., Dunne, J. P., John, J. G., Adcroft, A. J., Griffies, S. M., Hallberg, R. W., Shevliakova, E., Stouffer, R. J., Krasting, J. P., Phillipps, P. J., Wittenberg, A. T., Zadeh, N., 2012. GFDL's ESM2 global coupled climate-carbon earth system models. part I: physical formulation and baseline simulation characteristics. dx.doi.org 25 April(19), 6646-6665.

Copland, L., Mueller, D.R., Weir, L., 2007. Rapid loss of the Ayles ice shelf, Ellesmere island, Canada. Geophys. Res. Lett. 34 (21), L21501.

Death, R., Siegert, M.J., Bigg, G.R., Wadley, M.R., 2006. Modelling iceberg trajectories, sedimentation rates and meltwater input to the ocean from the Eurasian ice sheet at the last glacial maximum. Palaeogeogr. Palaeoclimatol Palaeoecol. 236 (1-2), 135-150.

Death, R., Wadham, J.L., Monteiro, F., Le Brocq, A.M., Tranter, M., Ridgwell, A., Dutkiewicz, S., Raiswell, R., 2014. Antarctic ice sheet fertilises the southern ocean. Biogeosciences 11 (10), 2635-2643.

Delworth, T.L. Broccoli, A.J., Rosati, A., Stouffer, R.J., Balaji, V., Beesley, J.A. Cooke, W.F., Dixon, K.W., Dunne, J., Dunne, K.A., Durachta, J.W., Findell, K.L., Ginoux, P., Gnanadesikan, A., Gordon, C.T., Griffies, S.M., Gudgel, R., Harrison, M.J., Held, I.M., Hemler, R.S., Horowitz, L.W., Klein, S.A., Knutson, T.R., Kushner, P.J. Langenhorst, A.R., Lee, H.-C., Lin, S.-J., Lu, J., Malyshev, S.L., Milly, P.C.D., Ramaswamy, V., Russell, J., Schwarzkopf, M.D., Shevliakova, E., Sirutis, J.J., Spelman, M.J., Stern, W.F., Winton, M., Wittenberg, A.T., Wyman, B., Zeng, F. Zhang, R.,2006. GFDL's CM2 global coupled climate models. part I: formulation and simulation characteristics. J. Clim. 19 (March(5)), 643-674.

Duprat, L.P.A.M., Bigg, G.R., Wilton, D.J., 2016. Enhanced southern ocean marine productivity due to fertilization by giant icebergs. Nat. Geosci. 9 (March(3)), 219-221.

Gladstone, R.M., Bigg, G.R., Nicholls, K.W., 2001. Iceberg trajectory modeling and meltwater injection in the Southern Ocean, 106. Norwegian Meteorological Institute, pp. 19903-19915. C9

Henderson, J., Loe, J.S.P., 2016. The prospects and challenges for arctic oil development. Oil, Gas Energy Law J. (OGEL) 14 (May(2)).

Hunke, E.C., Comeau, D., 2011. Sea ice and iceberg dynamic interaction. J. Geophys. Res. 116 (May(C5)), C05008.

Jongma, J.I., Driesschaert, E., Fichefet, T., Goosse, H., Renssen, H., 2009. The effect of dynamic-thermodynamic icebergs on the southern ocean climate in a three-dimensional model. Ocean Modell. 26 (1-2), 104-113.

Jongma, J.I., Renssen, H., Roche, D.M., Mar. 2013. Simulating Heinrich event 1 with interactive icebergs. Clim. Dyn. 40 (5-6), 1373-1385.

Joughin, I., Smith, B.E., Medley, B., 2014. Marine ice sheet collapse potentially under way for the Thwaites glacier basin, west Antarctica. Science 344 (6185), 735-738.

Levine, R.C., Bigg, G.R., 2008. Sensitivity of the glacial ocean to Heinrich events from different iceberg sources, as modeled by a coupled atmosphere-iceberg-ocean model. Paleoceanography 23 (4).

MacAyeal, D.R., Scambos, T.A., Hulbe, C.L., Fahnestock, M.A., 2003. Catastrophic ice-shelf break-up by an ice-shelf-fragment-capsize mechanism. J. Glaciol. 49 (164), 22-36.

Marsh, R., Ivchenko, V.O., Skliris, N., Alderson, S., Bigg, G.R., Madec, G., Blaker, A.T., Aksenov, Y., Sinha, B., Coward, A.C., Le Sommer, J., Merino, N., Zalesny, V.B., 2015 NEMO-ICB (v1.0): interactive icebergs in the NEMO ocean model globally configured at eddy-permitting resolution. Geosci. Model Dev. 8 (5), 1547-1562.

Martin, T., Adcroft, A., 2010. Parameterizing the fresh-water flux from land ice to ocean with interactive icebergs in a coupled climate model. Ocean Modell. 34 (3-4), 111-124.

Menemenlis, D., Campin, J.M., Heimbach, P., 2008. ECCO2: high resolution global ocean and sea ice data synthesis. Mercator Ocean Quarterly Newslett. 31, 13-21.

Merino, N., Le Sommer, J. Durand, G., Jourdain, N.C., Madec, G., Mathiot, P., Tournadre, J., 2016. Antarctic icebergs melt over the southern ocean: climatology and impact on sea ice. Ocean Modell. 104 (August), 99-110.

Pizzolato, L., Howell, S.E.L., Derksen, C., Dawson, J., Copland, L., 2014. Changing sea ice conditions and marine transportation activity in Canadian Arctic waters between 1990 and 2012. Clim Change 123 (March(2)), 161-173.

Rackow, T., Wesche, C., Timmermann, R., Hellmer, H.H., Juricke, S., Jung, T., Mar. 2017. A simulation of small to giant Antarctic iceberg evolution: differential impact on climatology estimates. J. Geophys. Res.

Rignot, E., Kanagaratnam, P., Feb. 2006. Changes in the velocity structure of the Greenland ice sheet. Science 311 (5763), 986-990.

Rignot, E., Velicogna, I., van den Broeke, M.R., Monaghan, A., Lenaerts, J., 2011. Acceleration of the contribution of the Greenland and Antarctic ice sheets to sea level rise. Geophys. Res. Lett. 38, L05503. 
Roberts, W.H.G., Valdes, P.J., Payne, A.J., 2014. A new constraint on the size of Heinrich events from an iceberg/sediment model. Earth Planet. Sci. Lett. 386, 1-9.

Savage, S.B., 2001. Aspects of iceberg deterioration and drift. In: Geomorphological Fluid Mechanics. Springer Berlin Heidelberg, pp. 279-318. December

Silva, T.A.M., Bigg, G.R., Nicholls, K.W., 2006. Contribution of giant icebergs to the southern ocean freshwater flux. J. Geophys. Res. 111 (March(C3)).

Smith, K.L.J., Sherman, A.D., Shaw, T.J., Sprintall, J., 2013. Icebergs as unique lagrangian ecosystems in polar seas. Ann. Rev. Mar. Sci. 5 (1), 269-287.

Stern, A.A., Adcroft, A., Sergienko, O., 2016. The effects of Antarctic iceberg calvingsize distribution in a global climate model. J. Geophys. Res. 121 (July), JC011835.

Stern, A.A., Johnson, E., Holland, D.M., Wagner, T.J.W., Wadhams, P., Bates, R., Abrahamsen, E.P., Nicholls, K.W., Crawford, A., Gagnon, J., Tremblay, J.-E., Aug. 2015. Wind-driven upwelling around grounded tabular icebergs. J. Geophys. Res. 120 (8), 5820-5835.

Stokes, C.R., Tarasov, L., Blomdin, R., Cronin, T.M., Fisher, T.G., Gyllencreutz, R., Hattestrand, C., Heyman, J., Hindmarsh, R.C.A., Hughes, A.L.C., Jakobsson, M., Kirchner, N., Livingstone, S.J., Margold, M., Murton, J.B., Noormets, R., Peltier, W.R., Peteet, D.M., Piper, D.J.W., Preusser, F., Renssen, H., Roberts, D.H., Roche, D.M., Saint-Ange, F., Stroeven, A.P., Teller, J.T., 2015. On the reconstruction of palaeo-ice sheets: recent advances and future challenges. Quat. Sci. Rev. 125, $15-49$.
Unger, J.D., 2014. Regulating the Arctic gold rush: recommended regulatory reforms to protect Alaska's Arctic environment from offshore oil drilling pollution. Alaska L. Rev. 31, 263.

van den Berk, J., Drijfhout, S.S., 2014. A realistic freshwater forcing protocol for ocean-coupled climate models. Ocean Modell. 81 (September), 36-48.

Vernet, M., Smith, K.L.J., Cefarelli, A.O., Helly, J.J., Kaufmann, R.S., Lin, H., Long, D.G. Murray, A.E., Robison, B.H., Ruhl, H.A., Shaw, T.J., Sherman, A.D., Sprintall, J. Stephenson, G.R.J., Stuart, K.M., Twining, B.S., 2012. Islands of ice: influence of free-drifting antarctic icebergs on pelagic marine ecosystems. Oceanography 25 (September(3)), 38-39.

Wagner, T.J.W., Dell, R.W., Eisenman, I., 2017. An analytical model of iceberg drift. J. Phys. Oceanogr. 47 (July), 1605-1616.

Wagner, T.J.W., Eisenman, I., 2017. How climate model biases skew the distribution of iceberg meltwater. Geophys. Res. Lett. 26 (January(2)), 113.

Weeks, W.F., Mellor, M., 1978. Some Elements of Iceberg Technology. Technical report. Cold Regions Research and Engineering Laboratory. March

Wiersma, A.P., Jongma, J.I., 2010. A role for icebergs in the $8.2 \mathrm{ka}$ climate event. Clim. Dyn. 35 (August(2-3)), 535-549. 


\title{
Supplementary Information for "On the representation of capsizing in iceberg models"
}

\author{
Till J.W. Wagner, Alon A. Stern, Rebecca W. Dell, and Ian \\ EISENMAN
}

\section{Derivation of rolling stability criterion}

Here we present a derivation of the iceberg rolling stability criterion, $\epsilon_{c}$, by considering the torques acting on the iceberg after a given rotation, $\theta$. Note that this is an alternative approach to the previous derivation by MacAyeal et al (2003), who minimized the potential energy of the system in order to find $\epsilon_{c}$.

Consider the cross-section of a cuboid iceberg of height $H$ and width $W$. The iceberg is taken to float at isostatic equilibrium, with densities of water $\rho_{w}$ and ice $\rho_{i}$. For a given angle of rotation, $\theta$, the horizontal position of the center of gravity, $x_{g}$, can be seen to be

$$
x_{g}=-\left(D-\frac{H}{2}\right) \sin \theta=-H\left(\frac{\rho_{i}}{\rho_{w}}-\frac{1}{2}\right) \sin \theta,
$$

(with the origin chosen to be located at the point of rotation, $R$, as indicated in Fig S1). Here $D \equiv\left(\rho_{i} / \rho_{w}\right) H$ is the draft of the iceberg, and $D-H / 2$ is the distance between $R$ and $x_{g}$ (Fig. S1). The center of buoyancy, $x_{b}$, is readily derived by sectioning the submerged area of the iceberg into a triangle $(a, b, c)$ with area $A_{1}$ and center of buoyancy horizontal coordinate $x_{1}$ and a rectangle $(\mathrm{a}, \mathrm{c}, \mathrm{d}, \mathrm{e})$ with area $A_{2}$ and center of buoyancy horizontal coordinate $x_{2}$, as indicated in Fig S1:

$$
x_{b}=\frac{x_{1} A_{1}+x_{2} A_{2}}{A_{1}+A_{2}} .
$$

Note that this is only satisfied for $|\theta|<\tan ^{-1}\left[2\left(1-\rho_{i} / \rho_{w}\right) H / W\right]$, which is the angle for which the lowest point of the iceberg's top surface is equal to the water surface.

The horizontal locations of the triangle vertices $\left(x_{a}, x_{b}, x_{c}\right)$ can be seen to satisfy $x_{a} \cos \theta=-W / 2, x_{b} \cos \theta=W / 2$, and $x_{c}-x_{a}=W \cos \theta$. This implies that

$$
x_{1}=\frac{1}{3}\left(x_{a}+x_{b}+x_{c}\right)=\frac{1}{3} x_{c}=\frac{W}{3}\left(\cos \theta-\frac{1}{2 \cos \theta}\right) .
$$

The horizontal locations of the additional rectangle vertices $\left(x_{d}, x_{e}\right)$ can be seen to satisfy $x_{a}-x_{e}=x_{c}-x_{d}=x^{\prime} \equiv\left(D-\frac{W}{2} \tan \theta\right) \sin \theta$, which implies that

$$
\begin{aligned}
x_{2} & =\frac{1}{4}\left(x_{a}+x_{c}+x_{d}+x_{e}\right)=\frac{1}{4}\left[x_{a}+x_{c}+\left(x_{c}-x^{\prime}\right)+\left(x_{a}-x^{\prime}\right)\right] \\
& =\frac{1}{2}\left(x_{a}+x_{c}-x^{\prime}\right)=\frac{1}{2}\left[-\frac{W}{\cos \theta}+W \cos \theta-\left(D-\frac{W}{2} \tan \theta\right) \sin \theta\right] .
\end{aligned}
$$




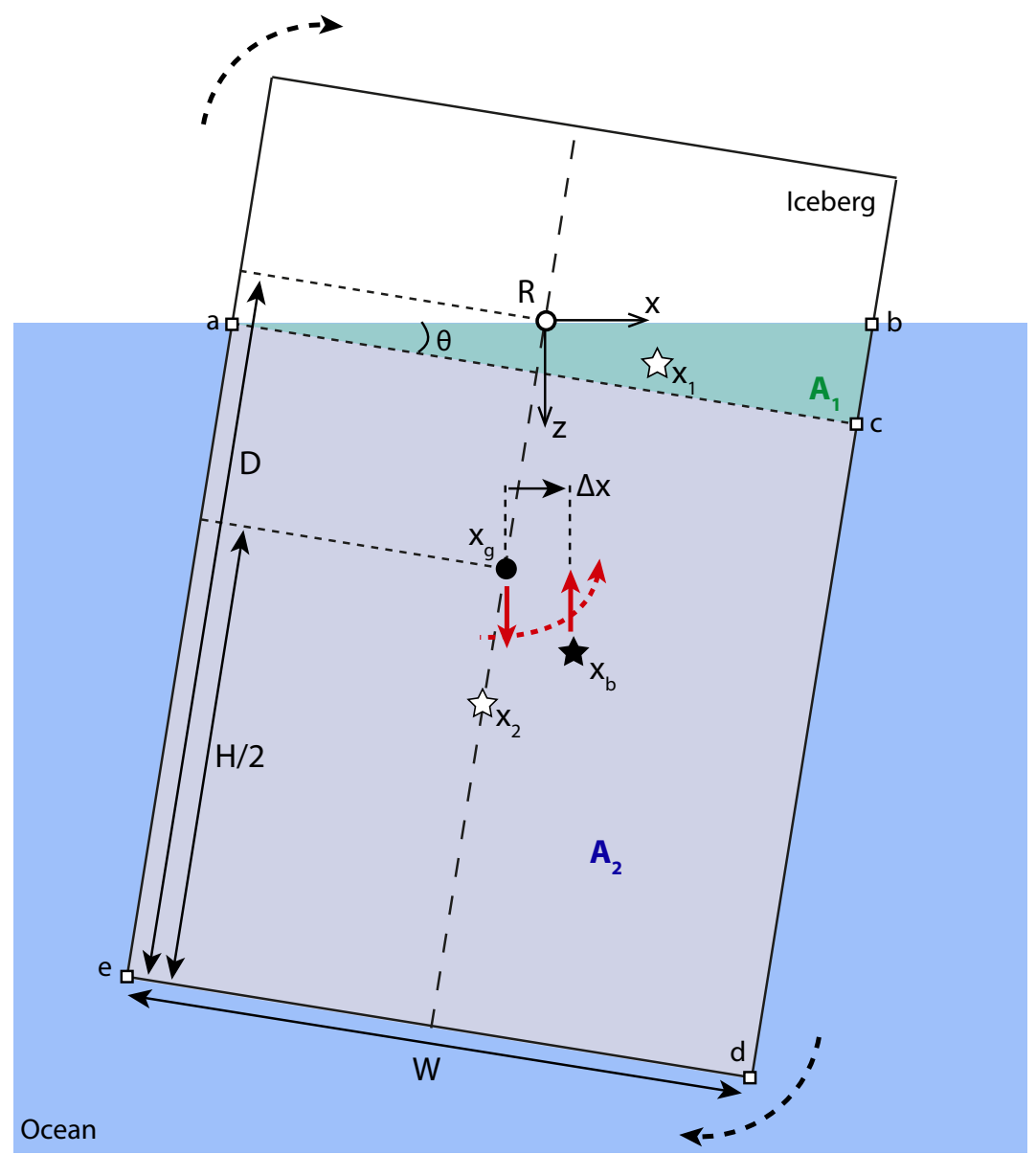

Figure S1. Schematic of an iceberg of width $W$ and height $H$, rotated clockwise by an angle $\theta$ (defined to be positive in this schematic). The center of rotation is shown at point $R(\circ)$. Indicated in blue and green are the two submerged areas, with auxiliary centers of buoyancy $(\boldsymbol{\zeta})$ used to compute the overall center of buoyancy $(\boldsymbol{\star})$. Also shown is the center of gravity $(\bullet)$, as well as the horizontal offset between the centers of buoyancy and gravity, $\Delta x=x_{b}-x_{g}$. The red arrows indicate the forces of gravity and buoyancy (solid) and the resulting torque (dashed). Since $\Delta x>0$ in the case illustrated, the resulting torque counteracts the rotation $\theta$, leading to a stable, self-righting, iceberg configuration.

Since $-1 / \cos \theta+\cos \theta=(1 / \cos \theta)\left(-1+\cos ^{2} \theta\right)=(1 / \cos \theta)\left(-\sin ^{2} \theta\right)=-\tan \theta \sin \theta$, this simpifies to

$$
\begin{aligned}
x_{2} & =\frac{1}{2}\left[-W \tan \theta \sin \theta-\frac{\rho_{i}}{\rho_{w}} H \sin \theta+\frac{W}{2} \tan \theta \sin \theta\right] \\
& =\frac{1}{2}\left[-\frac{W}{2} \tan \theta \sin \theta-\frac{\rho_{i}}{\rho_{w}} H \sin \theta\right] \\
& =-\frac{1}{2} \sin \theta\left(\frac{\rho_{i}}{\rho_{w}} H+\frac{W}{2} \tan \theta\right) .
\end{aligned}
$$


The submerged areas can be seen to be

$$
\begin{gathered}
A_{1}=\frac{1}{2}(W)(W \tan \theta)=\frac{1}{2} W^{2} \tan \theta \\
A_{2}=(W)\left(D-\frac{1}{2} W \tan \theta\right)=\frac{\rho_{i}}{\rho_{w}} H W-\frac{1}{2} W^{2} \tan \theta .
\end{gathered}
$$

Note that the total submerged area is thus $A_{1}+A_{2}=\left(\rho_{i} / \rho_{w}\right) H W$. Substituting equations $(\mathrm{S} 3)-(\mathrm{S} 6)$ into equation $(\mathrm{S} 2)$ and simplifying leads to

$$
x_{b}=\frac{\left[W^{2}-12\left(\frac{\rho_{i}}{\rho_{w}}\right)^{2} H^{2}\right] \sin \theta+W^{2} \sec \theta \tan \theta}{24 \frac{\rho_{i}}{\rho_{w}} H} .
$$

The horizontal distance between the center of gravity and the center of buoyancy can then be found from equations (S7) and (S1):

$$
\Delta x \equiv x_{b}-x_{g}=\frac{\left[12 \frac{\rho_{i}}{\rho_{w}}\left(\frac{\rho_{i}}{\rho_{w}}-1\right) H^{2}+W^{2}\right] \sin \theta+W^{2} \sec \theta \tan \theta}{24 \frac{\rho_{i}}{\rho_{w}} H} .
$$

We can simplify this somewhat by defining $\alpha \equiv \rho_{i} / \rho_{w}$ and $\epsilon \equiv W / H$ :

$$
\Delta x=\frac{H}{2}\left[\left(\alpha-1+\frac{1}{12 \alpha} \epsilon^{2}\right) \sin \theta+\frac{1}{12 \alpha} \epsilon^{2} \sec \theta \tan \theta\right]
$$

which corresponds to equation (1) in the main text. Performing a Taylor series in $\theta$ around 0 gives

$$
\Delta x=\frac{H}{2}\left(\alpha-1+\frac{\epsilon^{2}}{6 \alpha}\right) \theta+\mathcal{O}\left(\theta^{2}\right),
$$

which corresponds to equation (2) in the main text.

\section{Accounting for increasing density with depth}

Weeks and Mellor (1978) attempt to account for the density of an iceberg increasing with depth. This lowers the center of gravity by a distance $\Delta$. Weeks and Mellor (1978) consider an iceberg of thickness $H=200 \mathrm{~m}$, and they specify $\Delta=6 \mathrm{~m}$.

Upon rotation by $\theta$, the horizontal coordinate of the adjusted center of gravity, $x_{g}^{\prime}$, can be seen to be

$$
x_{g}^{\prime}=-H\left(\frac{\rho_{i}}{\rho_{w}}-\frac{1}{2}+\frac{\Delta}{H}\right) \sin \theta=x_{g}-\Delta \sin \theta,
$$

where $x_{g}$ is the value defined above $(\mathrm{S} 1)$ for an iceberg of uniform density. The adjusted horizontal distance between the center of buoyancy and the center of gravity is then

$$
\Delta x^{\prime}=\Delta x+\Delta \sin \theta .
$$

Computing a Taylor series for $\theta$ as above leads to

$$
\Delta x^{\prime}=\frac{H}{2}\left(\alpha-1+\frac{\epsilon^{2}}{6 \alpha}+\frac{2 \Delta}{H}\right) \theta+O\left(\theta^{2}\right) .
$$

Supplementary Information 
Solving for the critical value $\epsilon=\epsilon_{c}$, which occurs when $\Delta x^{\prime}=0$, gives

$$
\epsilon_{c}=\sqrt{6 \alpha(1-\alpha)-12 \alpha \frac{\Delta}{H}},
$$

which corresponds to equation (4) in the main text.

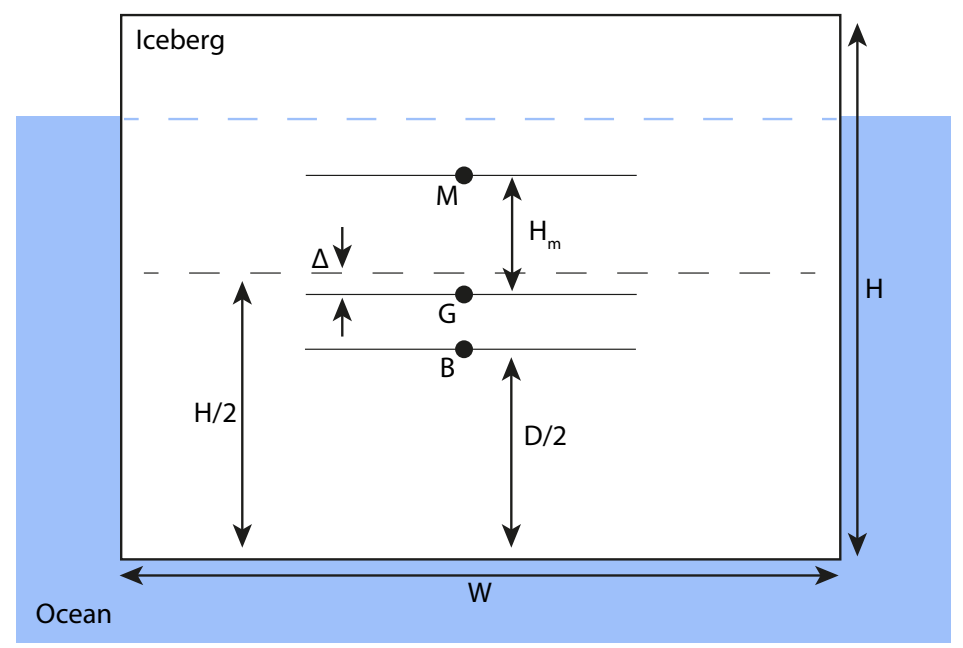

Figure S2. Schematic of a free-floating iceberg indicating the width $W$, height $H$, draft $D$, center of gravity $G$, center of buoyancy $B$, metacenter $M$, metacentric height $H_{m}$, and density correction $\Delta$.

\section{Rolling criterion as derived by Weeks \& Mellor (1978)}

Weeks \& Mellor (1978) determine the rotational stability of an iceberg using the metacentric height, $H_{m}$ (see Fig. S2). The metacentric height is defined as the vertical distance between the center of gravity $(G)$ and the metacenter $(M)$, such that $H_{m}=M-G$, and it is commonly used to assess the stability of ships. The metacenter is given by $M=I / A+B$, where $B$ is the center of buoyancy, $A$ is the submerged cross-sectional area, and $I=W^{3} / 12$ is the second moment of the area. The submerged area can be written as $A=\alpha H W$ and the center of buoyancy as $B=\alpha H / 2$. For an iceberg of uniform density, the center of gravity is simply at $G=H / 2$. However, WM78 account for an increase in ice density with depth, as described above. This is done by introducing a correction height, $\Delta$, such that $G=H / 2-\Delta$. The metacentric height can then be written as

$$
H_{m} \equiv \frac{I}{A}-(G-B)=\frac{W^{2}}{12 \alpha H}-\frac{H}{2}\left(1-\alpha-\frac{2 \Delta}{H}\right) .
$$

The iceberg will become unstable and roll over when $H_{m}<0$. Setting $H_{m}=0$ in equation (S10) and solving for the critical width-to-height ratio, $\epsilon \equiv W / H=\epsilon_{c}$, leads to

$$
\epsilon_{c}=\sqrt{6 \alpha(1-\alpha)-12 \alpha \frac{\Delta}{H}},
$$


which corresponds to equation (4) in the main text. However, Weeks \& Mellor (1978) erroneously determined the distance between the center of buoyancy and the center of gravity to be $B-G=H(1-\alpha) / 2+\Delta$, instead of the correct value $B-G=H(1-\alpha) / 2-\Delta$ (note that in their notation the iceberg height is given as $T)$. This leads to the erroneous stability criterion

$$
\epsilon_{c}=\sqrt{6 \alpha(1-\alpha)+12 \alpha \frac{\Delta}{H}}
$$

which was adopted in a number of subsequent studies, as discussed in the main text.

\section{Iceberg mass evolution for Northern and Southern Hemispheres}
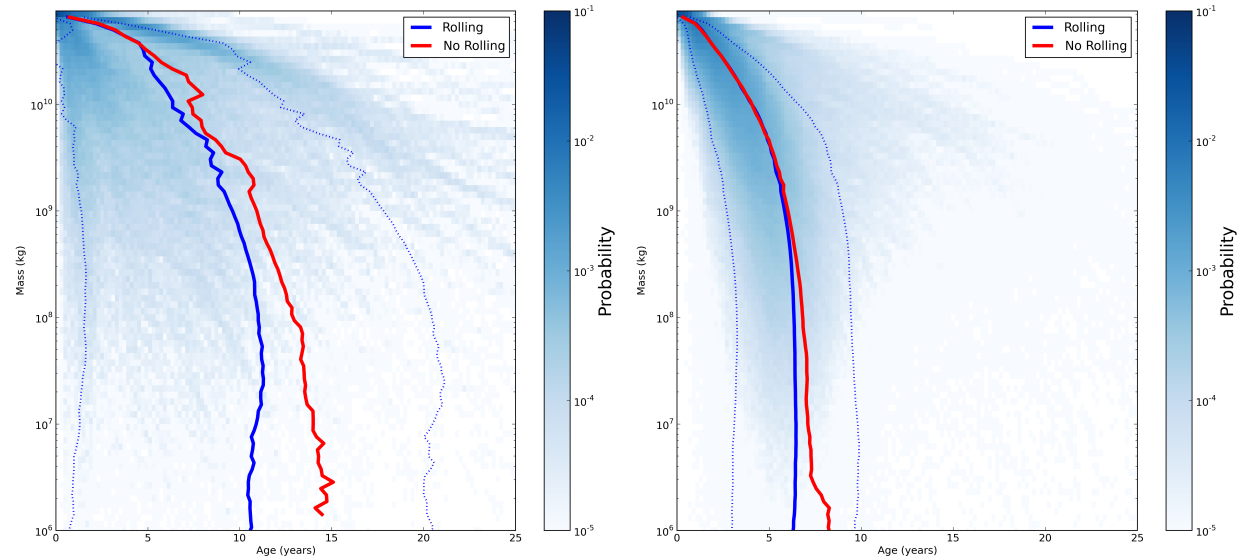

Figure S3. As Fig. 7 in the main text, but for Northern Hemisphere icebergs (left) and Southern Hemisphere icebergs (right). 